\title{
In This Issue: Size Matters
}

\author{
Kurt C. Stange, $M D, P b D$, Editor
}

Ann Fam Med 2016;14:2-3. doi: 10.1370/afm.1895.

$\mathrm{T}$ This issue of Annals examines matters of practice and panel size, use of technology by patients and clinicians, new ways of assessing home blood pressures and conducting research, high-risk patient groups, and reflective insights from practicing family physicians.

\section{ALTERNATIVES TO HOSPITAL-DOMINATED VERTICALLY INTEGRATED SYSTEMS}

For decades, pundits have predicted the demise of solo and small practices, and health care systems have been pushing policies that hasten their demise. And yet, small practices persist. A study by Liaw et al finds that most family physicians seeking board certification are in small and solo practices. Small practices constitute the largest category of practice size among physicians providing care in rural areas, and small or solo practice is more common among African American, Hispanic, and more experienced physicians. ${ }^{1}$ Medical home status and having a care coordinator are more common as practice size increases.

This research shows that amidst the rush toward increasing scale, which requires complicated, explicit, and often klunky systems, it may be important to not devalue smaller, local levels of scale in which simple, personal, often implicit systems may function well and meet the particular needs of both practitioners and disadvantaged populations. An editorial by Mostashari highlights the potentially vital role for small practices in a rapidly changing health care system. ${ }^{2}$ In another editorial, Glancey and Kennedy share an on-theground view of quality and payment from the perspective of an idealized micro practice. ${ }^{3}$

The opposite end of the size spectrum is revealed in a study by Casalino and colleagues, who identified and studied large, independent primary care medical groups. ${ }^{4}$ The size of these groups presents an opportunity for economies of scale, but what makes these practices particularly interesting is the combination of size and physician ownership. This gives them power to not only organize primary care, but to be an effective patient-focused force in organizing care and in selectively engaging narrowly focused care that is often both high risk and high cost. Large systems run by hospitals have very different incentives and perspectives.

A population-based study by Dahrouge examines the association of family physicians' panel sizes with quality of care and health service use. ${ }^{5}$ The complex findings are worthy of thoughtful interpretation. Among small practices, greater panel size is associated with slightly lower cancer screening and comprehensiveness of care, little difference in chronic disease management quality, greater hospitalization rates for ambulatory care-sensitive conditions, and lower rates of non-urgent emergency department visits. Continuity of care is highest with medium panel sizes. Clearly, practice panel size has complex effects, or at least correlates, that depend on local context and other factors.

What both small and very large independent practices have in common is an on-the-ground focus on the whole person. Their presence is a threat to the hegemony of hospital-dominated systems. Such systems can use their power to vertically integrate care, but are conflicted in providing patient-centered care when they compete over providing high-risk, high-cost care commodities, and are paid more to perform procedures than to focus holistically on patient needs. Even with more value-based payment, large hospital-dominated systems require very complex systems in order to perform the integrating, personalizing, prioritizing functions that are efficiently and effectively performed by primary care. ${ }^{6}$ Before it is too late to diversify the headlong rush toward a monoculture of vertically integrated, hospital-dominated systems, it is worth broadening the ideology and ecology of reform to test the hypothesis that higher-value personalization, integration, and sustainability may be provided by horizontally integrated systems based on independent large and small primary care practices that are well linked with mental health care and public health, and that selectively purchase vertical integration from hospitals and specialists. ${ }^{7-11}$

\section{TECHNOLOGY SUPPORTING PATIENTS, CLINICIANS, AND COMMUNICATION}

In a nationally representative sample, Serrano and colleagues identify a gradient of patients' willingness to 
exchange different kinds of information using mobile devices, and the characteristics of patients willing to engage in different kinds of electronic health information interchange. ${ }^{12}$ This is useful information for designing and implementing electronic information systems to meet the needs of different types of patients.

\section{HIGH-RISK GROUPS}

Among 3 durations of opioid use, Scherrer et al find that longer duration of use is associated with new onset of depression, whereas shorter durations (and dose) are not associated with incident depression. ${ }^{13}$

Another interesting incidence study finds a high rate of new depressive symptoms in a consecutive sample of adult patients presenting for care in primary care practices in a Hong Kong practice-based research network. The rate of incident depression is lower among patients seen by physicians with qualifications in both family medicine and psychological medicine, implying the possibility of a preventive benefit of seeing clinicians with joint training. ${ }^{14}$

Asgary and colleagues find a very high rate of uncontrolled hypertension among adults using homeless shelters. ${ }^{15}$ Interestingly, those with multiple chronic conditions have better hypertension control, as do those with insurance.

\section{NEW METHODS FOR ASSESSING HOME BLOOD PRESSURE AND FOR STUDYING DIVERSE GROUPS}

Until now, clinicians have not had an empirically validated method for assessing a patient's home blood pressure beyond informally looking over a list of home blood pressure readings. The study by Sharman et al, featured in Annals Journal Club, finds that the percentage of the last 10 home systolic blood pressures $\geq 135$ mm HG provides a reasonable estimate of the reference standard of 24-hour ambulatory blood pressure. ${ }^{16}$

In the research realm, Fetters et al develop a novel split-session method for conducting focus groups, in which time is divided between sessions with the entire group and with subgroups. ${ }^{17}$ The researchers find this method useful in a specific application to studying physicians and staff members in primary care practices.

\section{REFLECTIONS FROM EXPERIENCE}

Two essayists share wisdom from lives in practice.

Ventres shares, in both written and video formats, ${ }_{1}^{18}$ his personal ethos of healing. For Shani, a tempestuous patient stirs up a storm and wise reflections from his physician on the meaning of sleepless nights. ${ }^{19}$

We welcome your reflections at http://www.Ann FamMed.org.

\section{References}

1. Liaw WR, Jetty A, Petterson S, Peterson LE, Bazemore A. Solo and small practices: a vital, diverse part of primary care. Ann Fam Med. 2016;14(1):8-15.

2. Mostashari F. The paradox of size: how small, independent practices can thrive in value-based care. Ann Fam Med. 2016;14(1):5-7.

3. Glancey KK, Kennedy JG. Achieving PCMH status may not be meaningful for small practices. Ann Fam Med. 2016;14(1):4-5.

4. Casalino LP, Chen MA, Staub CT, Press MJ, Mendelsohn JL, Lynch JT, Miranda Y. Large independent primary care medical groups. Ann Fam Med. 2016;14(1):16-25.

5. Dahrouge S, Hogg W, Younger J, Muggah E, Russell G, Glazier RH. Primary care physician panel size and quality of care: a populationbased study in Ontario, Canada. Ann Fam Med. 2016;14(1):26-33.

6. Starfield B, Shi LY, Macinko J. Contribution of primary care to health systems and health. Milbank Q. 2005;83(3):457-502.

7. De Maeseneer J, van Weel C, Egilman D, Mfenyana K, Kaufman A, Sewankambo N. Strengthening primary care: addressing the disparity between vertical and horizontal investment. Br. J. Gen. Pract. 2008;58(546):3-4.

8. Thomas P, Meads G, Moustafa A, Nazareth I, Stange KC. Combined horizontal and vertical integration of care: a goal of practice-based commissioning. Qual Prim Care. 2008;16(6):425-432.

9. Robinson JC, Miller K. Total expenditures per patient in hospitalowned and physician-owned physician organizations in California. JAMA. 2014;312(16):1663-1669.

10. Casalino LP, Pesko MF, Ryan AM, et al. Small primary care physician practices have low rates of preventable hospital admissions. Health Aff. (Millwood). 2014;33(9):1680-1688.

11. Baker LC, Bundorf MK, Kessler DP. Vertical integration: hospital ownership of physician practices is associated with higher prices and spending. Health Aff. (Millwood). 2014;33(5):756-763.

12. Serrano KJ, Yu M, Riley W, et al. Willingness to exchange health information via mobile devices: findings from a population-based survey. Ann Fam Med. 2016;14(1):34-40.

13. Scherrer JF, Salas J, Copeland L, et al. Prescription opioid duration, dose and increased risk of depression in 3 large patient populations. Ann Fam Med. 2016;14(1):54-62.

14. Chin W, Wan E, Choi E, Chan K, Lam C. The 12-month incidence and predictors of $\mathrm{PHQ}-9$-screened depressive symptoms in Chinese primary care patients. Ann Fam Med. 2016;14(1):47-53.

15. Asgary R, Alcabes A, Naderi R, Schoenthaler A, Ogedegbe O, Sckell B. Rates and predictors of uncontrolled hypertension among hypertensive homeless adults using New York City shelter-based clinics. Ann Fam Med. 2016;14(1):41-46.

16. Sharman JE, Blizzard L, Kosmala W, Nelson M. Pragmatic method to assess blood pressure control from home blood pressure diaries. Ann Fam Med. 2016;14(1):63-69.

17. Fetters MD, Guetterman TC, Power D, Nease DE. Split-session focus group interviews in the naturalistic setting of family medicine offices. Ann Fam Med. 2016;14(1):70-75.

18. Ventres W. Healing. Ann Fam Med. 2016;14(1):76-78.

19. Shani M. White nights. Ann Fam Med. 2016;14(1):79-80. 